
coverage and benefit packages are less extensive in Asia.

The increase in public health spending over recent decades varied substantially across countries (see Chart 1). Among the 21 advanced economies for which data were available, between 1980 and 2008 public health spending increases exceeded 2.5 percent of GDP in 6 countries and were less than 1.5 percent of GDP in another 6. Among the 23 emerging economies, the public health spending ratio increased by more than 1 percent in 4 countries between 1995 and 2007 and actually fell in 6 .

\section{Stressing the system}

Public health spending ratios are projected to increase over the next two decades (see Chart 2). For the advanced economies, our projections are based on analysis of country spending trends between 1980 and 2008; for emerging economies, we assumed costs would grow as they had on average between 1995 and 2007. We also incorporated the effect of demographic changes on future health care spending in the projections for both advanced and emerging economies.

Public health spending ratios in advanced economies are projected to continue climbing, rising on average by 3 percent of GDP over the next 20 years. Spending is projected to increase by more than 2 percent of GDP in 14 of the 27 advanced economies, at a time when countries will need to reduce budget deficits and public debt ratios in the wake of the global financial crisis. The outlook is particularly grim in the United States, where public health spending is projected to rise by about 5 percent of GDP over the next 20 years, the highest among advanced economies. And in Europe, public health spending is expected to rise by 2 percent of GDP on average-and more than 3 percent in seven countries.

In emerging economies, public health spending is projected to rise by 1 percent of GDP over the next 20 years, onethird of advanced economies' projected increase. Consistent with past trends, spending is projected to rise by $1 \frac{1 / 2}{2}$ percent of GDP in both emerging Europe and Latin America; in emerging Asia, increases are expected to be about half that amount, reflecting in part low initial levels of spending in these countries.

\section{Containing public spending}

Recent health care reforms in advanced economies are unlikely to alter long-term public health spending trends. In the United States, the Patient Protection and Affordable Care Act of 2010 introduces a sweeping reform that will expand health insurance coverage but is expected to reduce the budget deficit, primarily through increased payroll taxes on individuals and families with relatively high incomes and an excise tax on generous health care plans. While these reforms can expand access, the envisaged savings on health care spending are small and remain highly uncertain. In Europe, plans to cut government employment and compensation could reduce health care spending in the short term, but their long-term effect is uncertain.

The most promising strategies to contain spending in advanced economies involve a mix of instruments to contain costs and reforms to improve spending efficiency:

- Budget caps with central oversight are a powerful tool for restraining expenditures. Among the countries with the lowest public spending increases in the past, Italy, Japan, and Sweden rely more on budget caps. Setting budgets for hospitals and other health care institutions based on reasonable and objective expenditure projections, as opposed to simply reimbursing all spending, can help contain spending growth. Such targets are most effective when applied broadly: partial constraints encourage expenditure increases in areas without caps. For example, if only inpatient hospital spending is limited, expenditures on outpatient clinics may increase.

\section{Chart 2}

\section{Under pressure}

Public health care spending is projected to rise by 3 percent of GDP in advanced economies, and by 1 percent of GDP in emerging economies, with regional variations.

$$
\text { Advanced economies }
$$

(change in public health spending, percent of GDP, 2011-30)

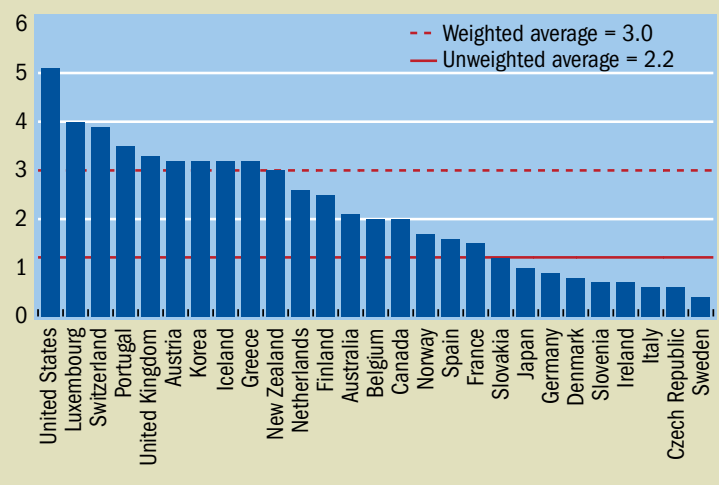

Emerging economies

(change in public health spending, percent of GDP, 2011-30)

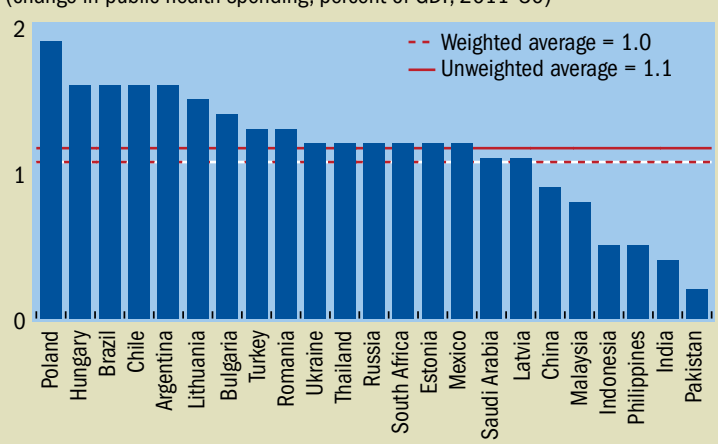

Source: IMF staff estimates. 
- Public management and coordination of health care services help control health care costs by screening out unnecessary services. For example, gatekeeping, through which a primary care physician manages a patient's health care services and coordinates referrals to specialists, is widely considered crucial to constraining the growth of costly hospital treatment. Countries with low spending growth that make extensive use of gatekeeping include Denmark and Italy.

- Local and state government involvement in key health resource decisions can help tailor services to local conditions, increasing spending efficiency. It can also help control

\section{The large inefficiencies in spending in many countries suggest there is much room to contain cost increases without compromising health.}

growth in expenditures when coupled with increased responsibility, so that local governments bear the cost of health care inefficiencies or overruns. Canada and Sweden have combined extensive local government involvement with low-cost growth.

- The use of market mechanisms in the health care system-increasing patient choice of insurers, allowing greater competition between insurers and providers, and relying on more private services-can help reduce costs by improving the efficiency of the health care system. Germany and Japan score relatively high in this area and have enjoyed low spending growth in the past. Moving away from simple reimbursement of provider costs toward more sophisticated management and contracting systems that include built-in incentives for providers to minimize waste and improve services also enhances spending efficiency. Examples of such contracting reforms include payment for health services based on "diagnostic related groups," which specify treatment protocols for a given set of medical conditions and provide an associated price schedule. These have been used with relative success in Germany and Italy.

- Reforms that increase the share of costs borne by patients, through either higher copayments or expanded private insurance, have also been successful in containing the growth of public health spending. Australia, Canada, and France rely heavily on private insurance for services not covered by the public package. In all countries, cost-sharing policies raise concerns about fairness and must be accompanied by measures to ensure that the poor and chronically ill retain access to basic health services.

- Restricting the supply of health inputs or outputs-for example, by rationing high-technology equipment-can, to some extent, reduce the growth of public health spending. Canada and France rely on such controls and are among the countries with low spending growth. But supplier responses can erode direct price controls on medical inputs or outputs (such as drugs or wages of health care providers): for example, primary care providers may direct patients to more expensive hospital care in response to price or quantity controls. In practice, therefore, price controls have often proved ineffective in containing health care costs. And while giving users more information about the quality and price of particular health care services may increase the quality of medical services, it has not helped contain spending.

\section{Potential impact}

We used various techniques, including case studies and regression analysis, to examine the potential for health care reforms to contain rising costs. The case studies provide country-specific examples of successful reforms, and regression analysis helped quantify the impact.

Our analysis shows that such reforms could significantly reduce the fiscal burden of health care over the next 20 years (see Chart 3). We assume countries that now score below the mean on the health system characteristics that reduce spending-such as the use of budget caps-are raised to the mean. The results suggest that the introduction of market mechanisms can be powerful, yielding savings of about $1 / 2$ percent of GDP. Improving public management and coordination can reduce spending by only a slightly lower amount. The analysis also underscores the importance of tighter budget controls and greater central oversight, which can reduce spending by $1 / 4$ percent of GDP. Finally, the simulated impacts of demand-side reforms, such as the use of cost sharing, are small but not negligible. The relative importance and desirability of each of these reforms will vary across countries, depending on their current health care system.

The impact on people's health will of course be an important consideration as policymakers grapple with the challenges of health care reform. Fortunately, most of the promising strategies we describe above can increase the health care system's responsiveness to patients' needs while taming spending. The large inefficiencies in spending in many countries suggest there is much room to contain cost increases without compromising health.

Chart 3

\section{Taming the beast}

Health care reforms could help offset projected expenditure increases.

(decrease in projected healthcare spending relative to baseline in 2030 as a result of given reform, percent of GDP)

0.5

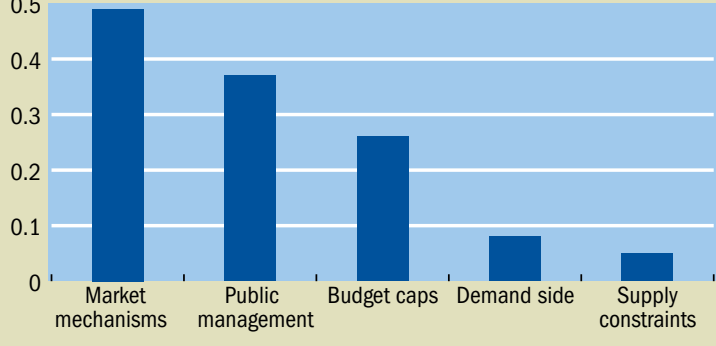

Sources: OECD Health Database; and IMF staff estimates.

Note: Unweighted averages of the impact of reforms. 
Health care reform requires continuous monitoring and refinement based on current data about the behavior of providers and patients, if costs are to be contained over the long term. Successful cost-cutting calls for continuous tweaking and reformulation of reform initiatives as players adapt to the new rules of the game and find ways around them. Reforms' effectiveness must be watched carefully to ensure that providers, insurers, and patients are responding as expected to cost-cutting incentives.

\section{Complementary policies}

Greater emphasis on preventive care could also help slow the growth of health care spending. Health is affected by factors other than public health spending, including individuals' income and personal habits. Governments can play an important role in promoting good health habits by encouraging people to stop smoking, use alcohol in moderation, eat better, exercise more, and drive carefully. Market mechanisms can also have an impact. For example, linking cost sharing or insurance premiums to obligatory regular checkups can reinforce preventive care and help contain spending.

While the estimated impact of the proposed reforms is substantial, it may not be enough to stabilize ratios of public spending to GDP, especially in countries where large spending increases are projected. In that case, additional efforts (beyond a movement to the mean performance on these health system characteristics) would be needed to stabilize public spending ratios, including spending cuts in other, non-health-care, areas or increases in revenue.

\section{Diverse challenges in emerging economies}

Emerging economies, where average life expectancy is lower and infant mortality higher, face different public health spending challenges than advanced economies. Emerging economies can learn valuable lessons from the experience of advanced economies, and should aim to expand their health care systems while avoiding the inefficiencies and resulting high costs that plague many advanced economies.

In emerging Europe, spending is relatively high by emerging economy standards, because of nearly universal coverage and, as in advanced economies, a pattern of diseases that is expensive to treat (such as diabetes and heart disease). In most countries in emerging Europe, overall health is relatively poor compared with advanced economies, and funds to improve health are limited. These countries will need to rely more on efficiency-enhancing reforms to improve health outcomes.

Emerging economies in Asia and Latin America have lessextensive health coverage than emerging Europe, but more scope to expand spending. To ensure coverage for as many people as possible, at an affordable cost, public health systems should focus first on providing the most essential health services. There should be greater emphasis on preventive and primary care, which will require a change in financial incentives for health care providers. And governments should allocate a larger share of their health care spending to infectious disease control and better care in poor rural areas.
Some of the experiences of the advanced economies as they expanded health care coverage offer important lessons for emerging economies. In particular, Taiwan Province of China and Korea undertook important reforms to better align incentives for health providers, promote primary and preventive care, and improve public management and coordination. Taiwan Province of China, for example, introduced a fee-for-outcome program, with physicians receiving bonus payments based on clinical outcomes.

\section{In emerging economies, expanding basic services to a broader segment of the population is the best recipe for improving health in a fiscally sustainable manner.}

Social insurance systems can help contain the fiscal burden of health spending by linking eligibility for health benefits with contributions. But in many emerging economies there is a large informal labor market whose workers may not be making social insurance contributions. So if the goal is to expand coverage in emerging economies, tax-financed provision of universal basic health care (such as in Thailand) may be the best starting point.

Social insurance-based systems could be expanded in countries where the informal labor market figures less prominently and revenue administration is of high quality. Chile's experience suggests that health care financing can be sustained by a combination of mandatory contributions in the formal labor market, individual cost-sharing through copayments, and supplementary government budget financing (especially when subsidies are necessary and in the public interest).

Health care reform will continue to be a key fiscal policy challenge for policymakers in advanced and emerging economies alike. The lessons of the past suggest that a judicious mix of reforms can help contain spending growth in advanced economies while preserving equity and efficiency. In emerging economies, expanding basic services to a broader segment of the population is the best recipe for improving health in a fiscally sustainable manner.

\section{Benedict Clements is a Division Chief, David Coady is a Deputy Division Chief, and Baoping Shang is a Technical Assistance Advisor, all in the IMF's Fiscal Affairs Department. Justin Tyson is a Senior Economist in the IMF's European Department.}

\footnotetext{
References:

International Monetary Fund, 2010, "Macro-Fiscal Implications of Health Care Reform in Advanced and Emerging Economies," IMF Policy Paper (Washington, December).

Sivard, R., 1974-96, World Military and Social Expenditures (Leesburg, Virginia: WMSE Publications), various issues.
} 